\title{
Modeling and Measuring Organization Capital
}

\author{
Andrew Atkeson \\ University of California, Los Angeles, Federal Reserve Bank of Minneapolis, and National \\ Bureau of Economic Research
}

\section{Patrick J. Kehoe}

Federal Reserve Bank of Minneapolis, University of Minnesota, and National Bureau of Economic Research

\begin{abstract}
Manufacturing plants have a clear life cycle: they are born small, grow substantially with age, and eventually die. Economists have long thought that this life cycle is driven by organization capital, the accumulation of plant-specific knowledge. The location of plants in the life cycle determines the size of the payments, or organization rents, plant owners receive from organization capital. These payments are compensation for the interest cost to plant owners of waiting for their plants to grow. We use a quantitative growth model of the life cycle of plants, along with U.S. data, to infer the overall size of these payments.
\end{abstract}

Micro data on U.S. manufacturing plants reveal a clear life cycle: like their biological counterparts, manufacturing plants are born small, grow substantially as they age, and eventually die (see, e.g., Davis, Haltiwanger, and Schuh 1996). Economists have long thought that this life cycle is driven by the accumulation of plant-specific knowledge, which we call organization capital. Theory suggests that where plants are in the life cycle determines the size of the payments, or organization rents, plant

We thank the National Science Foundation for research support and Kathy Rolfe for excellent editorial assistance. The views expressed herein are those of the authors and not necessarily those of the Federal Reserve Bank of Minneapolis or the Federal Reserve System.

[Journal of Political Economy, 2005, vol. 113, no. 5]

(C) 2005 by The University of Chicago. All rights reserved. 0022-3808/2005/11305-0004\$10.00

1026 
owners receive from organization capital. These payments are compensation for the interest cost to plant owners of waiting for their plants to grow. Here we build a quantitative growth model of the life cycle of plants and use it, along with U.S. data, to measure the overall size of these payments. We find that the payments are quite large. In the model, the payments that owners receive from organization capital are more than one-third the size of the payments they receive from physical capital, net of new investment.

To give these numbers some additional context, we use McGrattan and Prescott's (2005) procedure to infer the total payments owners of manufacturing firms receive from all intangible capital in the U.S. National Income and Product Accounts (NIPA). This procedure implies that such payments to intangible capital are about 8 percent of U.S. manufacturing output. In our model, the payments to organization capital alone are about 40 percent of those payments.

Our model of organization capital builds on the industry evolution models of Jovanovic (1982), Nelson and Winter (1982), and Hopenhayn and Rogerson (1993). We model the accumulation of organization capital at the plant level. Each plant is distinguished by its specific productivity and its age, and this pair of distinguishing features is what we consider the plant's organization capital. The specific productivity of a plant depends on the vintage of the plant's technology and its built-up stock of knowledge on how to use that technology. When new plants are built, their blueprints embody the best available, or frontier, technology, but they have little built-up knowledge. As a plant operates over time, its specific productivity grows stochastically at a rate that depends on the plant's age. We interpret this growth of a plant's specific productivity as arising from a stochastic learning process.

The basic mechanics of payments in our model are as follows. In the model, the owners of a plant pay fixed costs to start and operate the plant. In return, the owners collect variable profits less the fixed costs of operation as organization rents over and above the rental payments for physical capital and labor. As the plant grows, so do these organization rents; hence, the life cycle of plants corresponds to a life cycle of organization rents: young plants tend to have low organization rents and older plants higher ones. In the model, an owner of an older plant has built up a type of intangible capital—organization capital-that entitles the owner to high organization rents.

In the aggregate, what payments to organization capital should we expect to see in a steady-state equilibrium? With free entry into the activity of starting plants, the present value of the stream of organization rents to the owners of new plants is, of course, zero. At any particular time, however, the total payments owners receive from organization capital are the sum of the dividend payments to owners of plants of all 
ages in the cross section. If interest rates are positive and plants have the typical back-loaded pattern of organization rents over the life cycle, then we expect the organization rents in the aggregate to be positive. These payments to owners compensate them for the interest cost of waiting for the plants to grow.

Our strategy for measuring the payments from organization capital is dictated by the mechanics of payments in the model. We build a quantitative model of the learning process that drives the life cycle of plants. The model then implies a corresponding life cycle of organization rents. We infer the payments to organization capital by summing these implied organization rents.

To quantify the learning process of plants in our model, we rely on the simple observation that the relative size of plants in the model is determined by their relative specific productivities. We calibrate the stochastic process by which plant productivity grows so that the model can reproduce panel data on employment, job creation, and job destruction in manufacturing plants of different ages in the U.S. economy.

When interpreted in the context of our model, these data on industry evolution indicate that learning is both prolonged and substantial. In the data, as a cohort of plants ages from newborn to 20 years old, for example, its share of the labor force grows by a factor of about seven. In our model, these data imply that the aggregate of specific productivities across a cohort of plants grows substantially for 20 years. More generally, our model replicates the patterns of plant birth, growth, and death in the U.S. economy and, hence, quantifies the accumulation of organization capital in this economy. With this quantitative model, we infer the payments to plant owners for organization capital directly rather than as a residual.

We model specific productivity as an exogenous stochastic process in a way similar to Hopenhayn and Rogerson's (1993). Our approach differs from that of a large literature that models specific productivity as endogenous. The main advantage of our approach is that it allows us to match the process for specific productivity directly to data on the growth process of plants. Moreover, we need not take a stand on whether this productivity is derived from active or passive learning, matching, or ongoing adoption of new technologies in existing plants.

The type of capital that we attempt to measure is one that has long been considered significant. At least as far back as Marshall (1930, bk. iv, chap. 13.I), economists have argued that organizations store and accumulate knowledge that affects their technology of production. This accumulated knowledge is a type of unmeasured capital distinct from the concepts of physical or human capital in the standard growth model. 
We think of this type of knowledge as driving the life cycle of plants and, hence, being the source of organization capital.

In terms of the literature, two broad themes have emerged since Marshall's work. One of those themes is that organization capital is a firm-specific or plant-specific capital good jointly produced with output and embodied in the organization itself. Rosen (1972), Ericson and Pakes (1995), and many others have developed models in which organization capital is acquired by endogenous learning by doing. We follow this theme and regard organization capital as embodied in the plant and as being jointly produced with measured output. In our model, this asset is transferable by selling the plant and payments to organization capital flow to owners of the plant.

A second broad theme in the literature is that organization capital is embodied in the firm's workers or in their matches to tasks within the firm. Jovanovic (1979), Prescott and Visscher (1980), Becker (1993), and others have developed explicit microeconomic models of this idea. Jovanovic and Moffitt (1990), Topel (1991), and others have measured different aspects of firm-specific human capital. Models that follow this theme have at least some of the payments to organization capital flow to workers, depending on how owners and workers divide the matchspecific quasi rents. (See Rosen [1972] for a useful discussion of how different types of organization capital lead to different patterns of payments to owners and workers.)

In our model, all payments to organization capital flow to owners of plants, and our empirical strategy is designed to measure these payments. Developing a model that builds on the second theme, in which some of the payments to organization capital flow to workers, and using that model to measure such payments in the data is an interestingand separate-exercise.

\section{The Life Cycle of Plants and Organization Capital: An Illustration}

In this section we illustrate the connection between the life cycle of plants and the measurement of payments to organization capital in a steady state in a simplified version of our model. We then discuss some extensions.

In the model, time is discrete and is denoted by periods $t=0,1$, 2, .... Production is carried out in plants. In any period, a plant is characterized by its age $s$, which determines its production function $f_{s}$. Each plant lives from age $s=0$ through age $s=N$. The economy is in a steady state with overlapping generations of plants arranged into $N+1$ cohorts, all of size one.

To operate, a plant pays a fixed cost $w_{m}$ in each period to use one 
unit of a fixed factor of production and hires labor $l$ at wage $w$ as a variable input. Output in a plant of age $s$ that hires $l_{s}$ units of labor is $y_{s}=f_{s}\left(l_{s}\right)$. The decision of how much labor to hire in a plant of age $s$ is static and is given by

$$
d_{s}=\max _{l} f_{s}(l)-w l,
$$

where $d_{s}$ is the variable profits of the plant. Employment in plants of cohort $s$ is denoted by $l_{s}$, which solves $f_{s}^{\prime}\left(l_{s}\right)=w$.

The organization rents (or profits) to the owner of the plant are the variable profits minus the fixed cost. The economy has free entry in starting new plants. This free entry implies that the discounted value of organization rents to the plant owner is zero, so that

$$
\sum_{s=0}^{N}\left(\frac{1}{1+i}\right)^{s}\left(d_{s}-w_{m}\right)=0,
$$

where $1+i$ is the real interest rate.

Here consumers and the definition of equilibrium are standard. In a steady state, the (gross) real interest rate $1+i$ is equal to $1 / \beta$, where $\beta$ is the consumer discount factor. The wage is such that the labor market-clearing condition $\sum_{s=0}^{N} l_{s}=1$ holds, and the free-entry condition (1) determines the price $w_{m}$ of the fixed factor.

The characteristics of a plant's life cycle are determined by the dependence of the plant's production function on its age. For example, if the marginal product of labor increases with age, then older plants will be larger, in that they hire more labor than younger plants. This plant life cycle gives rise to a life cycle of organization rents, defined as the time pattern of organization rents $d_{s}-w_{m}$.

The organization capital of a plant is also indexed by its age $s$. The basic idea is that the owners of a plant of age $s$ are entitled to the stream of organization rents that remain after operating costs are paid, $\left\{d_{s+k}-w_{m}\right\}_{k=0}^{N-s}$. These are, in effect, payments to the owners for the knowledge built up in the plants over time. Clearly, the free-entry condition (1) implies that the value of the organization capital of a plant of age 0 is zero. But if organization rents are back-loaded, in the sense that $d_{s}$ tends to rise with age, then the value of organization capital of plants of age $s>0$ is typically positive.

Consider now the income and product accounts of this economy. Aggregate output is the sum of output across plants, $\sum_{s=0}^{N} y_{s}$, and aggregate payments to labor and the fixed factor are also the relevant sum 
across plants, $\sum_{s=0}^{N}\left(w l_{s}+w_{m}\right)$. Consumers, in their role as owners of plants, are paid an amount equal to output less variable and fixed costs,

$$
\pi=\sum_{s=0}^{N} y_{s}-\sum_{s=0}^{N}\left(w l_{s}+w_{m}\right)
$$

which can be written as

$$
\pi=\sum_{s=0}^{N}\left(d_{s}-w_{m}\right)
$$

Note that $\pi$ is the cross-section aggregate amount of organization rents. We interpret $\pi$ as the payments to owners of plants as compensation for their organization capital, as measured in the income and product accounts of this economy.

Comparing (1) and (2) reveals that together the life cycle of organization rents and the real interest rate determine the payments owners receive for organization capital. If either the real interest rate $i$ is zero or organization rents do not vary with age, then these payments $\pi$ are zero. Alternatively, if the real interest rate is positive and organization rents are back-loaded, in that organization rents $d_{s}$ tend to grow with age, then these payments $\pi$ are positive. Moreover, the more back-loaded the organization rents, the larger the payments $\pi$.

A simple example illustrates the relationship between the back-loading of organization rents and the payments to organization capital. Let variable profits grow with plant age at rate $\gamma>1$, so that $d_{s}=\gamma^{s} d_{0}$. Then the free-entry condition (1) implies that the payments to the fixed factor are

$$
w_{m}=d_{0} \frac{\sum_{s=0}^{N}[\gamma /(1+i)]^{s}}{\sum_{s=0}^{N}[1 /(1+i)]^{s}}
$$

and the payments to organization capital are $\pi=d_{0}(N+1) \sum_{s=0}^{N} \gamma^{s} \omega_{s}$, where the weights $\omega_{s}$ are given by

$$
\omega_{s}=\frac{1}{N+1}-\frac{[1 /(1+i)]^{s}}{\sum_{s=0}^{N}[1 /(1+i)]^{s}} .
$$

These weights sum to zero and are monotonically increasing. Hence, payments to organization capital are increasing in the extent of backloading as indexed by $\gamma$.

Theoretically, at least, a perverse case may exist in which the organization rents could be so front-loaded that payments to organization capital would actually be negative. If, however, we add to the model the 
possibility of free exit, so that plants can exit at no cost, then optimality by plants implies that, at each age $n$,

$$
\sum_{s=n}^{N}\left(\frac{1}{1+i}\right)^{s}\left(d_{s}-w_{m}\right) \geq 0
$$

It is easy to show that under (3), the payments to organization capital (2) are always nonnegative, and as long as interest rates are positive, these payments are strictly positive whenever the dividend stream is not completely flat. ${ }^{1}$

Now we briefly describe several extensions of this simplified model.

First, in the simplified model we assumed that a fixed factor results in a fixed operating cost $w_{m}$. Adding an initial entry cost that simply gets subtracted from (1) and (2) is trivial. Doing so tends to increase the measured payments to organization capital in the cross section because it tends to increase the back-loading of organization rents.

Second, we have assumed that there is perfect competition and that variable profits arise because the variable factors have diminishing returns. Alternatively, variable profits may arise because of imperfect competition. Below we show that a model with free entry and imperfect competition is isomorphic to what we have here.

Third, in our model, all payments to organization capital are payments to the owners of plants, whereas workers are simply paid their static marginal product. If we introduce dynamic employment features that break the relationship between current wages and current marginal product, then some of the payments to labor will also be payments to a different form of organization capital. Several researchers, including Jovanovic (1979) and Prescott and Visscher (1980), have built models with these features. Quantifying the flow of payments to organization capital that are received by workers is an interesting and important exercise-but not one we are attempting.

Finally, in the next section, we extend the simple model to incorporate physical capital and uncertainty. We add these features so that we can compare the predictions of the model to the U.S. NIPA when we choose the model's parameters to reproduce U.S. data on the life cycle of plants.

$$
\begin{aligned}
& { }^{1} \text { Note that free exit for } n=N \text { and } n=N-1 \text { implies that } d_{N}-w_{m} \geq 0 \text { and } \\
& \qquad d_{N-1}-w_{m}+\left(\frac{1}{1+i}\right)\left(d_{N}-w_{m}\right) \geq 0 .
\end{aligned}
$$

Since $d_{N}-w_{m} \geq\left(d_{N}-w_{m}\right) /(1+i)>0$, we have that $d_{N-1}-w_{m}+d_{N}-w_{m} \geq 0$. The result then follows by induction. 


\section{A Model of Organization Capital}

We set up our model of organization capital in subsection $A$. In subsection $B$, we show how to use data on the size of plants over the life cycle to infer the corresponding life cycle of plant organization rents. Finally, in subsection $C$, we show how to extend the model to allow for imperfect competition.

\section{A. The Setup}

In our model, time is still discrete and is denoted by periods $t=0,1$, $2, \ldots$. The economy has a continuum of size one of households. Households have preferences over consumption given by $\sum_{t=0}^{\infty} \beta^{t} \log \left(c_{t}\right)$, where $\beta$ is the discount factor. Each household consists of a worker and a manager, each of whom supplies one unit of labor inelastically. Households are also endowed with the initial stock of physical capital and ownership of the plants that exist in period 0. Households face sequences of wages for workers, wages for managers, and intertemporal prices $\left\{w_{t}, w_{m}, p_{t} t_{t=0}^{\infty}\right.$; have initial capital holdings $k_{0}$; and own an initial asset value $a_{0}$ of the plants that exist in period 0 . Given all that, households choose sequences of consumption $\left\{c_{t}^{\infty} t_{t=0}^{\infty}\right.$ to maximize utility subject to the budget constraint:

$$
\sum_{t=0}^{\infty} p_{t} c_{t} \leq \sum_{t=0}^{\infty} p_{t}\left(w_{t}+w_{m t}\right)+k_{0}+a_{0} .
$$

Production in this economy is carried out in plants. In any period, a plant is characterized by its specific productivity $A$ and its age $s$. To operate, a plant uses physical capital and (workers') labor as variable inputs and one unit of a manager's time as a fixed factor. If a plant with specific productivity $A$ operates with one manager, capital $k$, and labor $l$, the plant produces output

$$
y=z A^{1-\nu} F(k, l)^{\nu},
$$

where the function $F$ is linearly homogeneous of degree one and the parameter $\nu \in(0,1)$. The technology parameter $z$ is common to all plants and grows at an exogenous rate. We call z economywide productivity. Following Lucas $(1978,511)$, we call $\nu$ the span of control parameter of a plant's manager. Here the parameter $\nu$ may be interpreted as determining the degree of diminishing returns at the plant level.

We refer to the pair $(A, s)$ as a plant's organization-specific capital, or simply its organization capital. This pair summarizes the built-up expertise that distinguishes one plant from another.

The timing of events in period $t$ is as follows. The decision whether to operate or not is made at the beginning of the period. Plants that 
do not operate produce nothing; the organization capital in these plants is lost permanently. Plants with organization capital $(A, s)$ that do operate, in contrast, hire a manager, capital $k_{t}$, and labor $l_{t}$ and produce output according to (5). At the end of the period, operating plants draw independent innovations $\epsilon$ to their specific productivity, with probabilities given by age-dependent distributions $\left\{\pi_{s}\right\}$. Thus a plant with organization capital $(A, s)$ that operates in period $t$ has stochastic organization capital $(A \epsilon, s+1)$ at the beginning of period $t+1$.

Consider the process by which a new plant enters the economy. Before a new plant can enter in period $t$, a manager must spend period $t-$ 1 preparing and adopting a blueprint for constructing the plant that determines the plant's initial specific productivity $\tau_{t}$. Blueprints adopted in period $t-1$ embody the frontier of knowledge regarding the design of plants at that point in time. These blueprints evolve exogenously, according to the sequence $\left\{\tau_{t}\right\}_{t=0}^{\infty}$. Thus a plant built in $t-1$ starts period $t$ with initial specific productivity $\tau_{t}$ and organization capital $(A, s)=$ $\left(\tau_{t}, 0\right)$. We refer to growth in $\tau_{t}$ as embodied technical change.

We assume that capital and labor are freely mobile across plants in each period. Thus, for any plant that operates in period $t$, the decision of how much capital and labor to hire is static. Given a rental rate for capital $r_{t}$, a wage rate for labor $w_{t}$, and a managerial wage $w_{m}$, the operating plant chooses employment of capital and labor to maximize static returns:

$$
\max _{k, l} z_{t} A^{1-\nu} F(k, l)^{\nu}-r_{t} k-w_{t} l-w_{m t}
$$

Letting $t$ denote dependence on rental prices and $z_{t}$, define

$$
d_{t}(A)=z_{t} A^{1-\nu} F\left(k_{t}(A), l_{t}(A)\right)^{\nu}-r_{t} k_{t}(A)-w_{t} l_{t}(A),
$$

where $k_{t}(A)$ and $l_{t}(A)$ are the solutions to this problem. Then the dividend earned by the owner of a plant with organization capital $(A, s)$ in $t$ is given by $d_{t}(A)$ minus the fixed cost of hiring the manager $w_{m}$. We refer to $d_{t}(A)$ as variable profits.

The decision whether or not to operate a plant is dynamic. This decision problem is described by the Bellman equation

$$
V_{t}(A, s)=\max \left[0, d_{t}(A)-w_{m t}+\frac{p_{t+1}}{p_{t}} \int_{\epsilon} V_{t+1}(A \epsilon, s+1) \pi_{s+1}(d \epsilon)\right],
$$

where the sequences $\left\{\tau_{t}, w_{t}, r_{t}, w_{m}, p_{t}^{\infty} t_{t=0}^{\infty}\right.$ are given. The value $V_{t}(A, s)$ is the expected discounted stream of returns to the owner of a plant with organization capital $(A, s)$. This value is the maximum of the returns from closing the plant and those from operating it. The second term on the right side of (8) is the expected discounted value of operating 
a plant of type $(A, s)$. It consists of current returns $d_{t}(A)-w_{m t}$ and the discounted value of expected future returns $V_{t+1}(A, s)$. The plant operates only if the expected returns from operating it are nonnegative. We let the plant operating decision $x_{t}(A, s)$ equal one if the plant operates at $t$ and zero otherwise.

The decision whether or not to hire a manager to prepare a blueprint for a new plant is also dynamic. In period $t$, this decision is determined by the equation

$$
V_{t}^{0}=-w_{m t}+\frac{p_{t+1}}{p_{t}} V_{t+1}\left(\tau_{t+1}, 0\right) .
$$

The value $V_{t}^{0}$ is the expected stream of returns to the owner of a new plant, net of the initial fixed cost $w_{m t}$ of paying a manager to prepare the blueprint for the plant.

Let $\mu_{t}$ denote the distribution in period $t$ of organization capital across plants that might operate in that period, where $\mu_{t}(A, s)$ is the measure of plants of age $s$ with productivity less than or equal to $A$. Let $\phi_{t} \geq 0$ denote the measure of managers preparing blueprints for new plants in $t$. Denote the measure of plants that operate in $t$ by $\lambda_{t}(A, s)$. This measure is determined by $\mu_{t}$ and the operating decision $x_{t}(A, s)$ according to

$$
\lambda_{t}(A, s)=\int_{0}^{A} x_{t}(a, s) \mu_{t}(d a, s) .
$$

For each plant that operates, an innovation to its specific productivity is drawn, and the distribution $\mu_{t+1}$ is determined from $\lambda_{t}, \phi_{t},\left\{\pi_{s}\right\}$, and $\left\{\tau_{t}\right\}$ as follows:

$$
\mu_{t+1}\left(A^{\prime}, s+1\right)=\int_{A} \pi_{s+1}\left(\frac{A^{\prime}}{A}\right) \lambda_{t}(d A, s)
$$

for $s \geq 0$ and $\mu_{t+1}\left(\tau_{t+1}, 0\right)=\phi_{t}$.

Let $k_{t}$ denote the aggregate physical capital stock. Then the resource constraints for physical capital and labor are $\sum_{s} \int_{A} k_{t}(A) \lambda_{t}(d A, s)=k_{t}$ and $\sum_{s} \int_{A} l_{t}(A) \lambda_{t}(d A, s)=1$. The resource constraint for aggregate output is $c_{t}+k_{t+1}=y_{t}+(1-\delta) k_{t}$, where $y_{t}$ is defined by

$$
y_{t}=z_{t} \sum_{s} \int_{A} A^{1-\nu} F\left(k_{t}(A), l_{t}(A)\right)^{\nu} \lambda_{t}(d A, s)
$$

and $\delta$ is the depreciation rate. The resource constraint for managers is $\phi_{t}+\sum_{s} \int_{A} \lambda_{t}(d A, s)=1$.

Managers are hired to prepare blueprints for new plants only if $V_{t}^{0} \geq 0$. Since there is free entry into the activity of starting new plants, 
in equilibrium we require that $V_{t}^{0} \phi_{t}=0$. Also, in equilibrium, $a_{0}=$ $\sum_{s} \int_{A} V_{0}(A, s) \mu_{0}(d A, s)$ is the value of the workers' initial assets.

Given a sequence of blueprints and economywide productivities $\left\{\tau_{t}\right.$, $\left.z_{t}\right\}$, initial endowments $k_{0}$ and $a_{0}$, and an initial measure $\mu_{0}$, an equilibrium in this economy is a collection of sequences of consumption and aggregate capital $\left\{c_{t}, k_{t}\right\}$; allocations of capital and labor across plants $\left\{k_{t}(A), l_{t}(A)\right\}$; measures of operating plants, potentially operating plants, and managers preparing plans for plants $\left\{\lambda_{t}, \mu_{t+1}, \phi_{t}\right\}$; value functions and operating decisions $\left\{V_{t}, V_{t}^{0}, x_{t}\right\}$; and prices $\left\{w_{t}, r_{t}, w_{m}, p_{t}\right\}$, all of which satisfy the above conditions.

\section{B. Linking Plant Size and Plant Organization Rents}

Now we link the variable profits $d_{t}(A)$ of a plant to the size of that plant as measured by its employment. We need this link because we calibrate the model to match U.S. data on the pattern of plant employment growth with age. We use this link as well to argue that our model will also match the evolution of variable profits of plants as they age. The corresponding life cycle of organization rents is given by $-w_{m t}$ and $d_{t}(A)-w_{m}$, where the fixed cost $w_{m t}$ is determined by the free-entry condition.

Consider the allocation of capital and labor across plants at any point in time. Since capital and labor are freely mobile across plants, this allocation problem is static. For convenience, for a given distribution $\lambda_{t}$ of organization capital, define

$$
n_{t}(A)=\left(\frac{A}{\bar{A}}\right)
$$

as the size of a plant of type $(A, s)$ in period $t$, where $\bar{A}_{t}=$ $\sum_{s} \int_{A} A \lambda_{t}(d A, s)$ is the aggregate of the specific productivities. The variable $n_{t}(A)$ measures the size of a plant in terms of its capital or labor or output, in that the equilibrium allocations are

$$
\begin{aligned}
k_{t}(A) & =n_{t}(A) k_{t}, \\
l_{t}(A) & =n_{t}(A) l_{t}, \\
y_{t}(A) & =n_{t}(A) y_{t},
\end{aligned}
$$

where $y_{t}=z_{t} \bar{A}_{t}^{1-\nu} F\left(k_{t}, l_{t}\right)^{\nu}$ is aggregate output. To see this, note that since the production function $F$ is linear homogeneous of degree one and there is only one fixed factor, all operating plants in this economy use physical capital and labor in the same proportions. The proportions are those that satisfy the resource constraints for capital and labor. 
The variable profits for a plant with organization capital $(A, s)$ are

$$
d_{t}(A)=(1-\nu) y_{t}(A)=(1-\nu) n_{t}(A) y_{t} .
$$

Variable profits $d_{t}(A)$ minus managerial wages $w_{m t}$ are the organization rents earned on organization capital. Hence, (13) links the size of plants $n_{t}(A)$ with their organization rents $d_{t}(A)-w_{m}$.

We define a steady-state growth path in this economy as an equilibrium in which the quality of the best available blueprint $\tau_{t}$ and aggregate plant productivity $\bar{A}_{t}$ grow at a constant rate $1+g_{\tau}$; the economywide level of productivity $z_{t}$ grows at a constant rate $1+g_{z}$; aggregate variables $y_{t}$, $c_{t}, k_{t}, w_{t}$, and $w_{m t}$ grow at a rate $1+g$, where $1+g=\left[\left(1+g_{z}\right)(1+\right.$ $\left.\left.g_{\tau}\right)^{1-\nu}\right]^{1 /(1-\nu \alpha)}$; variables $\phi_{t}, V_{t}^{0}$, and $r_{t}$ are constant; the productivity-age distributions of plants satisfy $\mu_{t+1}(A, s)=\mu_{t}\left(A /\left(1+g_{\tau}\right), s\right)$ and $\lambda_{t+1}(A$, $s)=\lambda_{t}\left(A /\left(1+g_{\tau}\right), s\right)$ for all $t, A$, and $s$; and

$$
\begin{aligned}
& V_{t+1}(A, s)=(1+g) V_{t}\left(\frac{A}{1+g_{\tau}}, s\right), \\
& d_{t+1}(A, s)=(1+g) d_{t}\left(\frac{A}{1+g_{\tau}}, s\right)
\end{aligned}
$$

for all $t, A$, and $s$.

It is worth pointing out two features of the steady state of our economy. First, in this steady state, data on the size-age distribution of plants do not pin down the span of control parameter $\nu$. Second, these data also do not pin down the extent to which technical change is embodied in blueprints or is economywide. (For details, see Atkeson and Kehoe [2003].)

\section{Adding Imperfect Competition}

So far we have assumed that the owners of plants earn variable profits because production at the plant level has diminishing returns, as indexed by $\nu$. Here we add imperfect competition and show that these variable profits arise as well when plants face downward-sloping demand. The main effect of adding imperfect competition to the model is that it scales up the amount of variable profits in the economy; hence, it scales up the size of the payments owners receive from organization capital.

Here each plant produces a differentiated product, which a competitive firm aggregates to produce a homogeneous final good. Each plant chooses its price and inputs to maximize profits given the downwardsloping demand from the firm that produces final goods. 
The competitive final goods firm produces output according to

$$
y_{t}=\left[\sum_{s} \int_{A} y_{t}(A)^{\theta} \lambda_{t}(d A, s)\right]^{1 / \theta}
$$

and has a static demand function $y_{t}(A)=p_{t}(A)^{-1 /(1-\theta)} y_{t}$. Note that we have imposed symmetry, in that all operating plants with the same $A$ choose the same output and set the same price. We have also normalized the price of the final good to be one. We adjust the notation of a plant's production function so that, in equilibrium, its variable profits are given by (13). Accordingly, we let the production function of a plant be given by

$$
y_{t}(A)=z_{t}^{1 / \theta} A_{t}^{(1-\gamma \theta) / \theta} F\left(k_{t}(A), l_{t}(A)\right)^{\gamma} .
$$

It is easy to show that the static maximization problem of a plant is given by (6) and (7) with $\nu=\gamma \theta$. Note that $\nu$ is the product of the diminishing returns parameter $\gamma$ from production and the parameter $\theta$, which governs the slope of the demand function. (Specifically, $\theta$ is the inverse of the equilibrium markup of price over marginal cost.) With this modification, the rest of the analysis is identical.

\section{Calibration and Measurement}

Now we bring the appropriate U.S. data into the model so as to infer the size of the payments to organization capital in the U.S. economy.

The model's macro parameters are taken either directly from McGrattan and Prescott (2005) or from our application of their method to the manufacturing sector as described in our Appendix A.

To match the model to observations, we follow McGrattan and Prescott and introduce a corporate profits tax $\tau_{c}$. We assume that this tax is levied on corporate profits measured as sales less compensation of employees and the depreciation of physical capital $\left(y_{t}-w_{t} l_{t}-w_{m t}-\delta k_{t}\right)$. We assume that these corporate tax revenues are rebated as a lumpsum payment to workers. Accordingly, the workers' Euler equation for physical capital implies that

$$
\frac{c_{t+1}}{\beta c_{t}}=\frac{1+g}{\beta}=1+i=\left(1-\tau_{c}\right)\left(\nu \alpha \frac{y_{t+1}}{k_{t+1}}-\delta\right)+1 .
$$

We use the values of $\beta=.98, g=2.02$ percent, and $i=4.1$ percent from McGrattan and Prescott's paper. Using the method we describe in Appendix A, we find that the depreciation rate $\delta=5.5$ percent, the capital share $k / y=1.46$, the corporate tax rate $\tau_{c}=48.1$ percent, and, hence, $\nu \alpha=19.9$ percent. Note that $\tau_{c}$ is computed by applying Poterba's (1998) method to manufacturing. As Poterba finds, the $\tau_{c}$ we 
measure is higher than the statutory corporate tax rate because $\tau_{c}$ includes the sum of the corporate profit and property tax burdens.

Now consider the parameter $\nu=\gamma \theta$. On the basis of the work of Basu and Fernald (1995), Basu (1996), and Basu and Kimball (1997), we choose $\theta=.9$, which implies a markup of 11 percent and an elasticity of demand of 10 . The parameter $\gamma$ measures the degree of diminishing returns in variable factors at the plant level. Hundreds of studies have used micro data to estimate production functions. These analyses incorporate a wide variety of assumptions about the form of the production technology and draw on cross-sectional, panel, and time-series data from virtually every industry and developed country. Douglas (1948) and Walters (1963) survey many studies. More recent work along these lines has also been done by Baily, Hulten, and Campbell (1992), Bahk and Gort (1993), Olley and Pakes (1996), and Bartelsman and Dhrymes (1998). From a survey of this work, we argue that in the context of a model like ours, $\gamma=.95$ is a reasonable value for this parameter. Using that value gives $\nu=.85$, which is consistent with the discussion of Atkeson, Khan, and Ohanian (1996).

In parameterizing the distributions of shocks to specific productivity, we assume that these shocks to size have a lognormal distribution, so that $\log \epsilon_{s} \sim N\left(m_{s}, \sigma_{s}^{2}\right)$. We choose the means $m_{s}$ and standard deviations $\sigma_{s}$ of these distributions to be smoothly declining functions of $s$. In particular, we set $m_{s}=\kappa_{1}+\kappa_{2}[(S-s) / S]^{2}$ for $s \leq S$ and $m_{s}=\kappa_{1}$ otherwise and $\sigma_{s}=\kappa_{3}+\kappa_{4}[(S-s) / S]^{2}$ for $s \leq S$ and $\sigma_{s}=\kappa_{3}$ otherwise. With this parameterization, the shocks for plants of age $S$ or older are drawn from a single distribution. Thus shocks to plant-specific productivity are parameterized by $\left\{\kappa_{i}\right\}_{i=1}^{4}$ and age $S$.

We choose the parameters governing these shocks so that the model matches data on the fraction of the labor force employed in plants of different age groups, as well as data on job creation and destruction in plants of different age groups, from the 1988 panel of the U.S. Census Bureau's Longitudinal Research Database (the LRD). ${ }^{2}$ We choose the data from this panel because it has the most extensive breakdown of plants by age. We think of choosing these statistics as analogous to choosing means and variances of shocks to productivity.

More formally, Davis et al. (1996) define the following statistics. Employment in a plant in year $t$ is $\left(l_{t}+l_{t-1}\right) / 2$, where $l_{t}$ is the labor force in year $t$. Job creation in a plant in year $t$ is $l_{t}-l_{t-1}$ if $l_{t} \geq l_{t-1}$ and zero

\footnotetext{
${ }^{2}$ Here and throughout, our microeconomic data are taken from the LRD on U.S. manufacturing plants (http://www.census.gov/econ/overview/ma0800.html). These data are broken down by crude age categories. In figs. 1 and 3, we use data from the 1988 panel of the LRD obtained from the computer disk that accompanies the book by Davis et al. (1996); these data are also available from Haltiwanger's Web site: http://www.bsos .umd.edu/econ/haltiwanger/.
} 
otherwise. Job destruction in a plant in year $t$ is $l_{t-1}-l_{t}$ if $l_{t} \leq l_{t-1}$ and zero otherwise. In figure 1, we report these three statistics for U.S. manufacturing plants in 1988 for all plants in each age category relative to the total employment in all plants. This gives us a total of 26 statistics from the data that we use to summarize the life cycle of plants.

We set the parameter $S=100$ and choose the four parameters $\left\{\kappa_{i}\right\}_{i=1}^{4}$ to minimize the sum of the squared errors between the corresponding 26 statistics computed from the model and those in the data. The resulting model statistics are also plotted in figure 1 . In figure 2, we plot the means and standard deviations of shocks to the log of the size of plants, $m_{s}$ and $\sigma_{s}$. The parameters that generate these shocks are $S=100, \kappa_{1}=-.1139, \kappa_{2}=.1741, \kappa_{3}=.1945$, and $\kappa_{4}=.0006$.

In figure $1 a$, we see that our model matches the U.S. employment shares fairly well. In figures $1 b$ and $c$, we see that our model implies a bit more job creation and destruction than are observed in the U.S. data. This is reflected in the implied statistics for the data and the model: the overall job creation and destruction rates are 8.3 percent and 8.4 percent for the data and 10.2 percent and 10.2 percent for the model. Note, however, that in annual data during 1972-93, the standard deviations of the overall job creation and destruction rates are 2.0 and 2.7 (see Davis et al. 1996). Hence, our model's overall job creation and destruction rates are within one standard deviation of the observed timeseries fluctuations in these rates.

\section{Industry Evolution in the Steady State}

We have calibrated our model to U.S. data on employment shares and job creation and destruction for plants in various age groups. In this section we compare the implications of our calibrated model to other important features of U.S. data on the birth, growth, and death of plants. We find that our model approximately captures most of these features. Hence, we argue that the model replicates the basic patterns of the accumulation of organization capital in the data.

Specifically, we compare our model to U.S. data on job destruction in failing plants, the distribution of employment growth rates by plants, and the distribution of labor and capital productivity in plants by age. We think of the data on job destruction in failing plants as measuring the failure rate of plants, in contrast to job destruction, which is the death rate of jobs. The data on the distribution of plant growth rates are a check on our assumption that the shocks to size are normally distributed. The data on plant productivity are a check on our model's implications that there is no systematic relation between plant age and capital and labor productivity.

First consider plant failure rates. In figure 3, we show the rate of job 

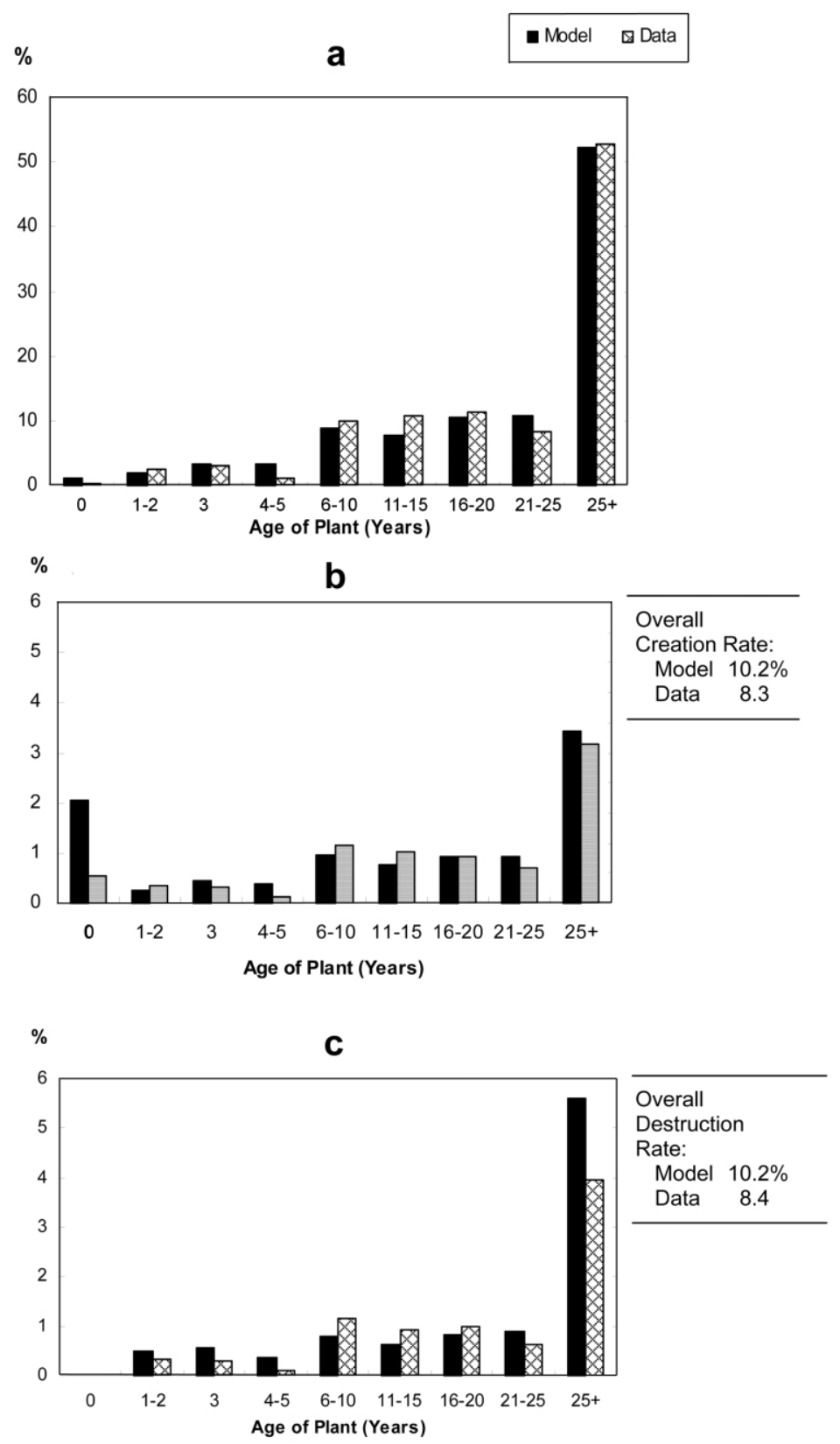

FIG. 1.-Employment statistics by manufacturing plant age in the model and in the 1988 U.S. data. $a$, Employment; $b$, job creation; $c$, job destruction. Data from Davis et al. (1996). 


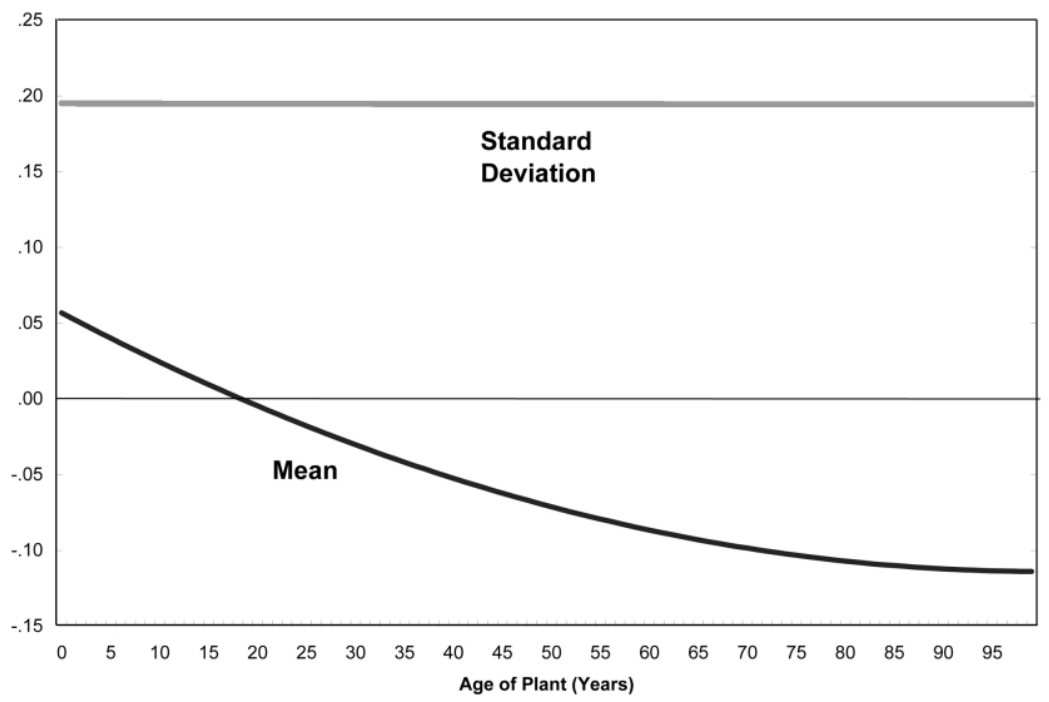

FIG. 2.-Means and standard deviations of shocks to plant size by age of plant

destruction in failing plants by age group for the model and the U.S. data. For each age group, job destruction in failing plants is the ratio of employment in plants that fail in that age group to total employment. This ratio has the interpretation of a size-weighted failure rate of plants. Overall, total job destruction in plants that fail is 3.1 percent in the model and 2.2 percent in the data. In this sense, the size-weighted failure

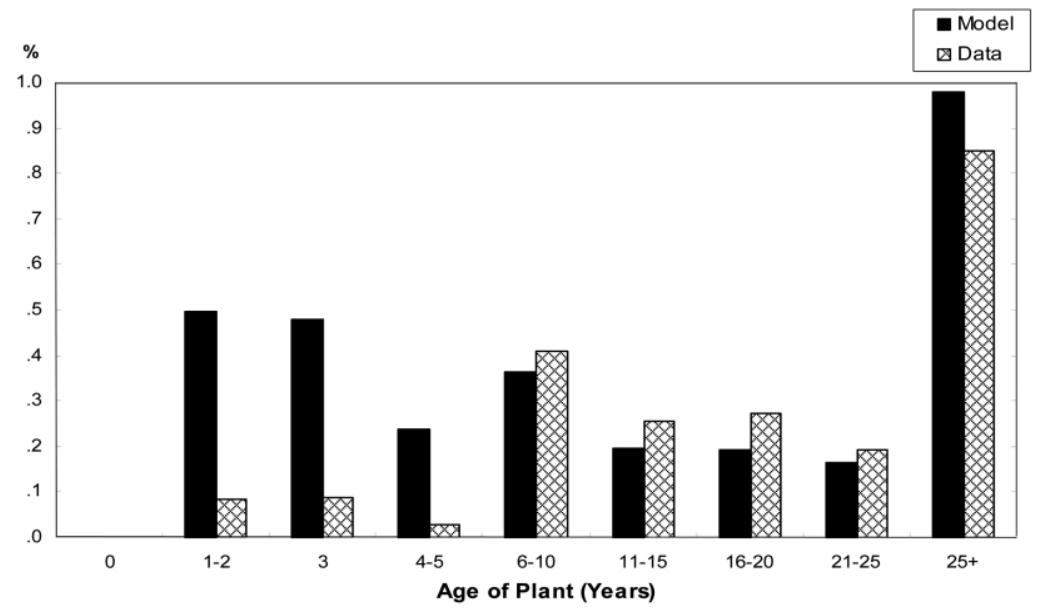

FIG. 3.-Job destruction in failing plants by age of plant (data from Davis et al. 1996) 


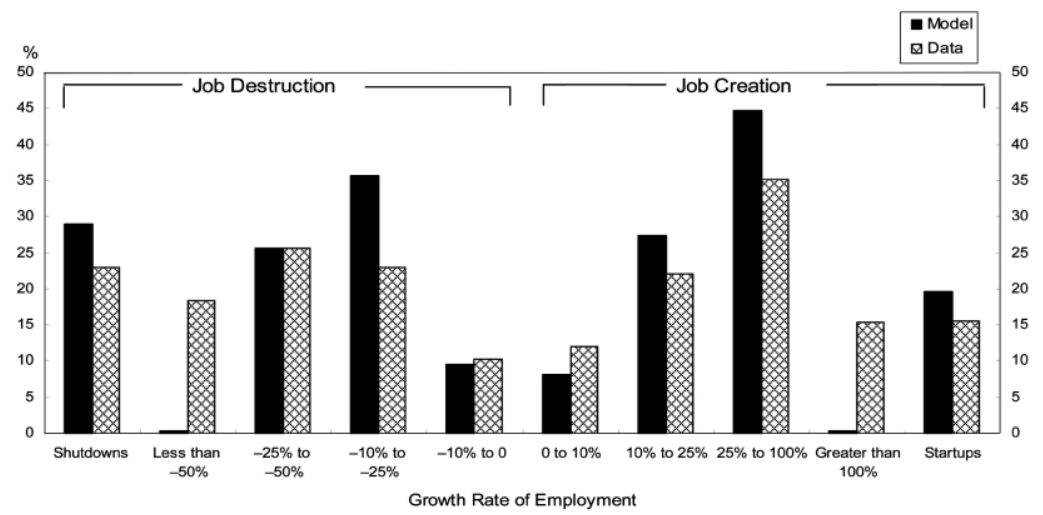

FIg. 4.-Distribution of job creation and destruction (data from Davis et al. 1996)

rate is higher in the model than in the data. This result is consistent with our earlier finding that the overall job destruction rate is higher in the model than in the data. (This discrepancy is largest for young plants. It follows from our model's overprediction in the employment in plants of age 0 as can be seen in figs. $1 a$ and $b$.)

Next consider the distribution of plant growth rates. In figure 4, we show the distribution of plant-level job creation and destruction in the model and the data. In this figure, we divide plants into 10 groups, on the basis of the plants' growth rate of employment (measured here by $G=\left[l_{t}-l_{t-1}\right] / l_{t-1}$ ), and show the fraction of total job creation (when $G$ is positive) and the fraction of total job destruction (when $G$ is negative) accounted for by plants in each group. ${ }^{3}$ For the data, we again draw on the work of Davis et al. (1996). In their data, a substantial amount of job creation comes from continuing plants that more than double in size ( 15.3 percent), and a substantial amount of job destruction comes from continuing plants that more than halve in size (18.4 percent). In our model with normally distributed shocks to size, shocks this large are more than three standard deviations from the mean and occur with extremely low probability. In order to match these extreme observations, we would need fatter-tailed distributions for the shocks.

Finally, consider the distributions of labor and capital productivity across plants by size and age. Our model predicts that at each point in time, both of these measures of productivity are constant across plants.

\footnotetext{
${ }^{3}$ For each plant, let $G_{i t}=\left(l_{i t}-l_{i t-1}\right) / l_{i t-1}$. Then, e.g., for the category [0,10 percent $]$, the statistic plotted is

$$
\frac{\sum_{\left\{i \mid G_{i t} \in[0,1]\right\}} l_{i t}-l_{i t-1}}{\sum_{i} \max \left\{0, l_{i t}-l_{i t-1}\right\}} .
$$
}




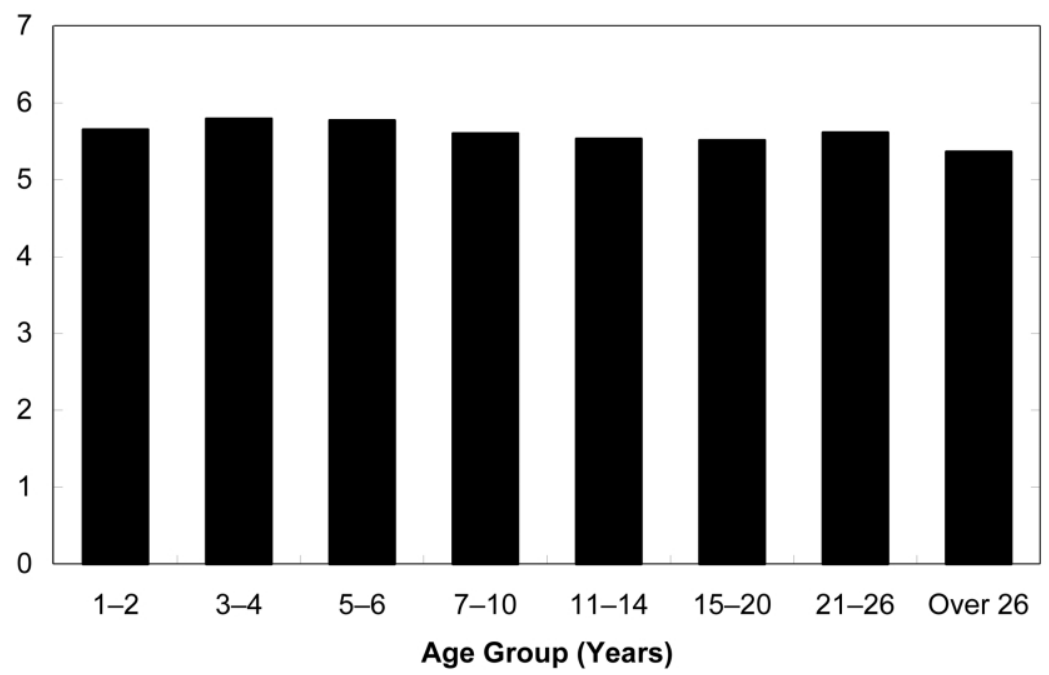

Fig. 5.-Average productivity of plants by age in U.S. data for 1972-86. Source: Bartelsman and Dhrymes (1998).

This implication follows immediately from our assumption that the production function is Cobb-Douglas. To see this, note that (12) implies that $y_{t}(A) / l_{t}(A)=y_{t} / l_{t}$ and $y_{t}(A) / k_{t}(A)=y_{t} / k_{t}$. For the data, Bartelsman and Dhrymes (1998) report, for a large sample of U.S. manufacturing plants drawn from the LRD, a geometric weighted average of capital and labor productivity

$$
\left(\frac{y_{i t}}{k_{i t}}\right)^{\alpha}\left(\frac{y_{i t}}{l_{i t}}\right)^{1-\alpha}
$$

by age group, where the weights $\alpha$ are obtained from a regression of outputs on inputs. In figure 5, we report the Bartelsman and Dhrymes values for this measure by age groups. Although Bartelsman and Dhrymes find substantial variations in average productivity across individual plants in their data, figure 5 demonstrates that they find no systematic relation between the average productivity of a plant and its age.

Jensen, McGuckin, and Stiroh (2001) find similar results in the data. They study labor productivity measured as value added per hour worked in a more extensive sample of U.S. manufacturing plants, also drawn from the LRD. They note that there is extensive variation in labor productivity across individual plants in their sample. When productivity is averaged across plants in a cohort, however, there seems to be no systematic relationship between labor productivity and age. Indeed, Jensen 
et al. report that after about five to 10 years, all cohorts of surviving plants have similar productivity levels.

\section{Measurement of Organization Capital}

In this section we report our model's measure of the share of output that is paid to owners of organization capital and the value of that capital relative to the value of physical capital. We also compare these findings to corresponding data for the U.S. manufacturing sector.

In our model, aggregate output is distributed among four factors: physical capital, workers, managers, and organization capital. To calculate these shares, recall that with imperfect competition the owners of physical capital and workers both receive less than their value marginal products-here, $\theta$ times their value marginal products. The share of output paid to owners of physical capital is $\nu \alpha$ (which equals $\theta \gamma \alpha$ ); to workers, $\nu(1-\alpha)$ (which equals $\theta \gamma[1-\alpha]$ ); and to managers, $w_{m} / y$; and the rest is paid to owners of organization capital. We have calibrated the physical capital share in the model to match that in the data, so that $\nu \alpha=19.9$ percent. The share of output paid to labor is the sum of the shares paid to workers and managers. With a span of control parameter $\nu=.85$, the share paid to workers is $\nu(1-\alpha)=65.1$ percent.

We now use the model to compute the division of the remaining 15 percent of output into the share paid to managers and the share paid to owners of organization capital. In the model, the managerial wage is determined by the condition that there be zero profits to starting new plants, namely, that $w_{m t}=\left[1 /\left(1+i_{t}\right)\right] V_{t+1}\left(\tau_{t+1}, 0\right)$.

In table 1, we report these shares for the data and the model, with

TABLE 1

Accounting for Output in the U.S. Manufacturing Sector

\begin{tabular}{|c|c|c|c|c|}
\hline & \multirow{2}{*}{$\begin{array}{c}\text { DATA ON U.S. } \\
\text { MANUFACTURING* }\end{array}$} & \multicolumn{3}{|c|}{ Model } \\
\hline & & $\nu=.80$ & $\nu=.85$ & $\nu=.90$ \\
\hline & \multicolumn{4}{|c|}{ Shares of Output (\%) } \\
\hline Labor & 72.2 & 75.7 & 76.8 & 77.9 \\
\hline Workers & $\ldots$ & 60.1 & 65.1 & 70.1 \\
\hline Managers & $\ldots$ & 15.6 & 11.7 & 7.8 \\
\hline Physical capital & 19.9 & 19.9 & 19.9 & 19.9 \\
\hline Intangible capital & 8.0 & $\ldots$ & & $\ldots$ \\
\hline \multirow[t]{2}{*}{ Organization capital } & $\ldots$ & 4.4 & 3.3 & 2.2 \\
\hline & \multicolumn{4}{|c|}{ Other Payments } \\
\hline $\begin{array}{l}\text { Net payments to physi- } \\
\text { cal capital }^{\dagger}\end{array}$ & 7.3 & 8.9 & 8.9 & 8.9 \\
\hline
\end{tabular}


several values for $\nu$. We start our discussion with $\nu=.85$. With our calibration, 11.7 percent of output is paid to managers, so that the share paid to labor is 76.8 percent and the share paid to owners of organization capital is 3.3 percent. In comparison, the shares in the data are 72.2 percent for labor and 8.0 percent for intangible capital. Our model thus accounts for about 41 percent (3.3/8.0) of the payments to owners of intangible capital in manufacturing. Since the shares in our model must sum to one, the remainder of the payments to owners of intangible capital, 4.7 percent $(8.0-3.3)$, must show up in another share. Since we calibrate the model to match the physical capital share of 19.9 percent, the remainder shows up as payments to managers and is thus added to the labor share, raising the total labor share in the model above that observed in the data.

The payments to owners of organization capital represent the payments net of the cost of the owners' investment in this capital. To put these payments in context, it is useful to compare them to the net payments that owners of physical capital receive after deducting the cost of new investment, that is, $r k-x$. In table 1 , we see that in the model the payments to owners of organization capital are 37 percent $(3.3 / 8.9)$ of the net payments to owners of physical capital.

Most of the parameters of our model are well measured. One has greater uncertainty than the rest, however: the span of control parameter $\nu$. How sensitive are our findings to this parameter? Consider raising $\nu$ from .85 to .90 or lowering it to .80 and, in each case, adjusting $\alpha$ so that the physical capital share $\nu \alpha$ is unchanged at 19.9 percent. With these changes in the span of control parameter-the results of which are also shown in table 1-the share of output paid to owners of organization capital falls from 3.3 percent to 2.2 percent or rises to 4.4 percent. Again, because the factor shares sum to one, the remainder of the unaccounted-for output is attributed to labor.

More generally, we can show that the payments to owners of organization capital relative to the sum of the payments to both owners of organization capital and managers are independent of $\nu$. To see this, note from (8) and (9) that the value functions and managerial wages are homogeneous of degree one in $1-\nu$. Thus, if we have two economies with the same shocks to plant size, one having span of control parameter $\nu$, managerial wages $w_{m}$, and value functions $V_{t}(A, s)$ and the other having span of control parameter $\tilde{\nu}$, managerial wages $\tilde{w}_{m}$, and value functions $\tilde{V}_{t}(A, s)$, then

$$
\frac{\tilde{V}_{t}(A, s)}{1-\tilde{\nu}}=\frac{V_{t}(A, s)}{1-\nu}
$$


and $\tilde{w}_{m t} /(1-\tilde{\nu})=w_{m t} /(1-\nu)$. Since $1-\nu$ is the sum of managerial wages and payments to owners of organization capital, the result follows.

In table 1 , we see that of the 15 percent share paid to owners of organization capital and managers together (with $\nu=.85$ ), organization capital owners get roughly one-quarter of the share and managers get the rest. Given the above result, this relation holds for all $\nu$. Hence, for any $\nu$, the organization capital share is roughly $(1-\nu) / 4$ and the managerial share is roughly $3(1-\nu) / 4$.

\section{Conclusion}

We have proposed a quantitative model of the life cycle of plants and demonstrated how it can be used to measure the payments to owners of a specific form of intangible capital directly, rather than as a residual. The key idea behind our model is that the owners of plants are making expenditures early in a plant's life cycle in order to reap organization rents in the future. We think of the activity of starting a new plant as a project of investing in organization capital that typically yields a backloaded life cycle pattern of organization rents. Because these organization rents are back-loaded, the aggregate payments to owners of plants for compensation for the investment in organization capital are positive. These payments correspond to the interest cost to plant owners of waiting for their plants to grow.

\section{Appendix A}

Payments to Owners of Intangible Capital in the U.S. NIPA

\section{A. Method}

McGrattan and Prescott (2005) present a method for computing the amount of payments to owners of intangible capital in the U.S. corporate sector. Here we apply their method to the U.S. manufacturing sector. We first describe a stripped-down version of the accounting procedure to give the basic idea, and then we go through the details of the actual calculation.

In the general procedure, net product for a given sector is given by

$$
\text { net product }=(r-\delta) k+w l+\pi,
$$

where $(r-\delta) k$ is the rental payments to measured capital net of depreciation, $w l$ is the compensation of labor, and $\pi$ is payments to intangible capital. Data on net product $N P$, depreciation $\delta k$, measured capital $k$, and compensation of labor $w l$ can be obtained from various issues of the U.S. National Income and Product Accounts produced by the U.S. Department of Commerce. The basic idea of the McGrattan-Prescott procedure is to impute the rental rate $r$ using the equilibrium condition that the return on measured capital $(r-\delta)$ should equal the return $i$ on other investments. Once this return $i$ is specified, payments to owners of intangible capital $\pi$ can be computed from (A1).

When we apply this basic idea to the manufacturing sector and use the NIPA, 
we must take into consideration sales taxes and corporate income taxes. First, since the value added is measured at consumer prices, it exceeds the value added of producers by the amount of sales taxes. Hence, we rewrite (A1) as

$$
\text { net product }- \text { sales taxes }=(r-\delta) k+w l+\pi \text {. }
$$

Next, when corporate income is taxed, the equilibrium condition is that the return on capital after corporate taxes $(1-\tau)(r-\delta)$ is equal to the return on other investments $i$, so that

$$
i=(1-\tau)(r-\delta) .
$$

Payments to intangible capital are thus

$$
\pi=\text { net product }- \text { sales taxes }-\frac{i}{1-\tau} k-w l .
$$

We measure the variables in (A4) as follows. Net product $(N P)$ is measured as the value added in manufacturing (VA) less consumption of fixed capital (CFC), which corresponds to $\delta k$.

The NIPA has no direct data on sales taxes paid in manufacturing. We use the method of Poterba (1998) to infer these taxes. The NIPA reports the taxes on production and imports less subsidies, which we denote by $I T$; it is essentially the sum of sales taxes $(S T)$ and property taxes $(P T)$. We estimate property taxes and then subtract them from IT to get our measure of sales taxes. Property taxes are estimated by multiplying the ratio of tangible assets in manufacturing to that of the economy as a whole by state and local property tax receipts (SLPTR). Here, as Poterba argues, property taxes are treated as part of the value added at producer prices, but sales taxes are not.

We measure $w l$ as the sum of compensation of employees $(C E)$ plus threequarters of proprietors' income $(P I)$. We include a portion of proprietors' income in our measure of $w l$ in order to capture payments to proprietors that are compensation for their labor input rather than their ownership of the means of production.

The variable $k$, which corresponds to measured capital, is constructed as the sum

$$
k=k_{E S}+k_{\text {inv }}+k_{\text {land }},
$$

where $k_{E S}$ represents fixed capital, the sum of equipment and structures; $k_{\text {inv }}$, the stock of inventories; and $k_{\text {land }}$, the stock of land.

To compute the tax rate $\tau$, we apply to manufacturing a procedure similar to that of Poterba (1998) and McGrattan and Prescott (2005). We take the sum of corporate profit taxes $(C T)$, property taxes $(P T)$, and business current transfers $(B T)$ and divide it by the sum of net product $(N P)$ minus sales taxes $(S T)$ minus $w l$, so that

$$
\tau=\frac{C T+P T+B T}{N P-S T-w l} .
$$

Here we are viewing business transfers as an implicit tax. These transfers consist primarily of liability payments for personal injury, corporate gifts to nonprofit institutions, and taxes paid by domestic corporations to foreign governments (see Seskin and Parker 1998). We view these transfers as a cost of doing business that owners of plants must pay.

The variable $i$ is the real interest rate, which we take from McGrattan and 
Prescott (2005). As McGrattan and Prescott have argued, this rate is the real interest rate after personal income taxes that a household would receive on an investment. In Appendix B we give a rationale for why this is the appropriate rate of return.

\section{B. Results}

We report the results of our decomposition in the familiar units of percentages of the value added, at producer prices (given by the value added at purchaser prices minus sales taxes). To translate our results into these units, we add depreciation to both sides of (A2) to get

$$
\text { value added }- \text { sales taxes }=\delta k+(r-\delta) k+w l+\pi \text {. }
$$

We find the following average shares over the period 1950-2001: $\delta k, 8.0$ percent; $(r-\delta) k, 11.9$ percent; $w l, 72.2$ percent; and $\pi, 8.0$ percent. In addition, the payments net of investment to owners of physical capital are $r k-x$, where $x$ denotes investment. We find that $r k-x$ relative to value added is 8.9 percent over the period 1950-2001. From these results, we find that, on average, the payments to owners of intangible capital, $\pi$, are 110 percent of the payments to owners of physical capital, net of investment, $r k-x$.

Notice that the NIPA measures only the total payments to owners of plants for both physical capital and intangible capital. The McGrattan-Prescott method decomposes these payments into the payments for physical capital and a residual, the latter of which is the payments to intangible capital. The decomposition is done by using separate data to set the real interest rate $i$ used to compute the payments to physical capital. There is a large literature, including work by Poterba (1998) and Larkins (2000), that investigates a logically separate question. That work supposes that there are no payments to intangible capital and finds the rate of return on physical capital that would lead the payments to physical capital to exhaust the total payments to owners of plants for both physical capital and intangible capital. Hall (2003) performs a related calculation. He assumes that, on average, there are no payments to intangible capital, and he finds the rental rate on physical capital that would lead the payments to physical capital to exhaust the total payments to owners of plants for both physical capital and intangible capital.

In our calculation of the tax rate $\tau$, we have followed Poterba (1998) in using a measure of the average tax burden on corporations. Some provisions, such as accelerated depreciation and the tax deductibility of interest payments, can lead the marginal tax burden to be lower than the average tax burden. If we redid our calculations with a lower tax rate for $\tau$ in (A4), we would obviously increase the McGrattan-Prescott measure of the payments to owners of intangible capital. In this sense, the McGrattan-Prescott measure of those payments is a conservative one.

\section{Sources}

The following variables come from various Gross Domestic Product by Industry accounts provided by the U.S. Commerce Department's Bureau of Economic Analysis (BEA): value added in manufacturing $V A$, taxes on production and imports less subsidies $I T$, business current transfer payments $B T$, and compen- 
sation of employees $C E$. (The data come from two spreadsheets: GDPbyInd VA_NAICS.xls and GDPbyInd_VA_SIC.xls.)

The following variables come from various issues of the U.S. Commerce Department's NIPA: state and local property tax receipts (SLPTR) from table 3.3, proprietors' income $(P I)$ from table 6.12, and inventories $\left(k_{\text {inv }}\right)$ from table 5.7.5. These data are quarterly. We take the data for the fourth quarter of each year to get the end-of-period stock corresponding to the end-of-period stocks for equipment and structures. Corporate profit taxes $(C T)$ are measured by taxes on corporate income in table 6.18.

The following variables come from the BEA's Fixed Assets tables. The variable $\delta k$, called consumption of fixed capital (CFC), is measured by the series called Current-Cost Depreciation of Private Fixed Assets by Industry in table 3.4ES in the September 2002 version of these tables. Investment in equipment and structures is taken from table $3.7 \mathrm{ES}$ in the same version. The variable $k_{E S}$, which measures the fixed capital, the sum of equipment and structures, is taken from the BEA data on fixed assets from table 3.1ES, Current-Cost Net Stock of Private Fixed Assets by Industry. These data are end-of-year stocks. We use the number for year $t$ at the beginning-of-year stock for year $t+1$.

The variable $k_{\text {land }}$, which measures the stock of land, is taken from the U.S. Labor Department's Bureau of Labor Statistics Web site, which includes data on its multifactor productivity program. (We use the zipped file k2dscdod.txt, which has a table on the stock of land in manufacturing in 1996 dollars, and the price deflator used to convert the stock of land to current dollars. This file is found by starting at http://www.bls.gov/web/prod3.supp.toc.htm and following the link to Capital Services by Asset Type for Major Sectors.) We thank a referee for pointing us to these data on land.

\section{Appendix B}

\section{The Appropriate Measure of the Real Interest Rate $i$ ?}

McGrattan and Prescott (2005) argue that in an economy in which corporate investments are financed out of retained earnings, the appropriate measure of $1+i$ in (A3) is the consumer's marginal rate of substitution, which equals the return that households can obtain on investments after personal income taxes. We demonstrate this result formally in a simple economy. In this economy, a representative household faces a constant personal income tax rate $\tau_{p}$ that applies equally to interest income, organization rents, and capital gains. A representative firm faces a constant corporate tax rate $\tau_{c}$. To keep the notation simple, we assume that this firm is all equity financed.

The household chooses consumption $c_{t}$, labor $l_{t}$, and shareholdings $s_{t}$ to maximize

$$
\max \sum_{t=0}^{\infty} \beta^{t} U\left(c_{t}, l_{t}\right)
$$

subject to a sequence of budget constraints

$$
c_{t}+q_{t} s_{t}=w_{t} l_{t}+\left(1-\tau_{p}\right) d_{t} s_{t-1}+q_{t} s_{t-1}-\tau_{p}\left(q_{t}-q_{t-1}\right) s_{t-1},
$$

where $q_{t}$ is the price of a share of the firm's organization rents from period 
$t+1$ onward, and $w_{t}$ is the real wage. The first-order conditions for consumption and shareholdings $s_{t}$ are that

$$
\beta^{t} U_{c t}=\lambda_{t}
$$

and

$$
\lambda_{t} q_{t}=\lambda_{t+1}\left[\left(1-\tau_{p}\right) d_{t+1}+q_{t+1}-\tau_{p}\left(q_{t+1}-q_{t}\right)\right],
$$

where $\lambda_{t}$ is the multiplier on the budget constraint. We convert the sequence of budget constraints in (B1) to a period 0 budget constraint by multiplying the constraints in (B1) by $\lambda_{t}$ and summing to obtain

$$
\sum_{t=0}^{\infty} \lambda_{t}\left(c_{t}-w_{t} l_{t}\right)=\sum_{t=0}^{\infty} \lambda_{t}\left[\left(1-\tau_{p}\right) d_{t} s_{0}\right]
$$

where $s_{0}=1$ in equilibrium. Note that the intertemporal price between periods $t$ and $t+1$ in this budget constraint is

$$
\frac{U_{c t}}{\beta U_{c t+1}}=\frac{\lambda_{t}}{\lambda_{t+1}}=\frac{\left(1-\tau_{p}\right) d_{t+1}+q_{t+1}-\tau_{p}\left(q_{t+1}-q_{t}\right)}{q_{t}}
$$

and, hence, is equal to the rate of return on equity, after personal income taxes.

The representative firm holds the physical capital stock $k_{t}$, pays corporate taxes $\tau_{c}$, and pays organization rents $d_{t}$, where

$$
d_{t}=F\left(k_{t}, l_{t}\right)-w_{t} l_{t}-x_{t}-\tau_{c}\left[F\left(k_{t}, l_{t}\right)-w_{t} l_{t}-\delta k_{t}\right] .
$$

Here $F$ is the production function, $x_{t}$ is investment (which is financed out of retained earnings), and $\delta$ is the depreciation rate. The capital accumulation law is $k_{t+1}=x_{t}+(1-\delta) k_{t}$.

Consider the consumer, acting as owner of the firm, choosing the objective function that the firm should maximize. It is clear from (B4) that the consumer would like the representative firm to maximize the right side of the consumer budget constraint. Hence, the firm's problem can be written as maximizing

$$
\left(1-\tau_{p}\right) \sum_{t=0}^{\infty} \lambda_{t} d_{t}
$$

subject to (B6) and the capital accumulation law. The first-order condition for capital $k_{t+1}$ can be written as

$$
\frac{\lambda_{t}}{\lambda_{t+1}}=1+\left(1-\tau_{c}\right)\left(r_{t+1}-\delta\right),
$$

where $r_{t+1}=F_{k t+1}$ is the marginal product of capital. Note that (B5) and (B7) together imply

$$
1+i_{t, t+1}=1+\left(1-\tau_{c}\right)\left(\tau_{t+1}-\delta\right)=\frac{U_{c t}}{\beta U_{c t+1}}
$$

\section{References}

Atkeson, Andrew, and Patrick J. Kehoe. 2003. "The Transition to a New Economy after the Second Industrial Revolution.” Staff Report no. 296, Res. Dept., Fed. Reserve Bank Minneapolis. 
Atkeson, Andrew, Aubhik Khan, and Lee Ohanian. 1996. "Are Data on Industry Evolution and Gross Job Turnover Relevant for Macroeconomics?" CarnegieRochester Conf. Ser. Public Policy 44 (June): 216-50.

Bahk, Byong-Hyong, and Michael Gort. 1993. "Decomposing Learning by Doing in New Plants." J.P.E. 101 (August): 561-83.

Baily, Martin Neil, Charles Hulten, and David Campbell. 1992. "Productivity Dynamics in Manufacturing Plants." Brookings Papers Econ. Activity: Microeconomics, 187-249.

Bartelsman, Eric J., and Phoebus J. Dhrymes. 1998. "Productivity Dynamics: U.S. Manufacturing Plants, 1972-1986.” J. Productivity Analysis 9 (January): 5-34.

Basu, Susanto. 1996. "Procyclical Productivity: Increasing Returns or Cyclical Utilization?" Q.J.E. 111 (August): 719-51.

Basu, Susanto, and John G. Fernald. 1995. "Are Apparent Productive Spillovers a Figment of Specification Error?” J. Monetary Econ. 36 (December): 165-88.

Basu, Susanto, and Miles S. Kimball. 1997. "Cyclical Productivity with Unobserved Input Variation.” Working Paper no. 5915 (February), NBER, Cambridge, MA.

Becker, Gary S. 1993. Human Capital: A Theoretical and Empirical Analysis, with Special Reference to Education. 3rd ed. Chicago: Univ. Chicago Press.

Davis, Steven J., John C. Haltiwanger, and Scott Schuh. 1996. Job Creation and Destruction. Cambridge, MA: MIT Press.

Douglas, Paul H. 1948. “Are There Laws of Production?” A.E.R. 38 (March): 141.

Ericson, Richard, and Ariel Pakes. 1995. "Markov-Perfect Industry Dynamics: A Framework for Empirical Work.” Rev. Econ. Studies 62 (January): 53-82.

Hall, Robert E. 2003. "Corporate Earnings Track the Competitive Benchmark." Working Paper no. 10150 (December), NBER, Cambridge, MA.

Hopenhayn, Hugo, and Richard Rogerson. 1993. "Job Turnover and Policy Evaluation: A General Equilibrium Analysis.” J.P.E. 101 (October): 915-38.

Jensen, J. Bradford, Robert H. McGuckin, and Kevin J. Stiroh. 2001. “The Impact of Vintage and Survival on Productivity: Evidence from Cohorts of U.S. Manufacturing Plants." Rev. Econ. and Statis. 83 (May): 323-32.

Jovanovic, Boyan. 1979. "Job Matching and the Theory of Turnover." J.P.E. 87, no. 5, pt. 1 (October): 972-90.

. 1982. "Selection and the Evolution of Industry." Econometrica 50 (May): 649-70.

Jovanovic, Boyan, and Robert Moffitt. 1990. "An Estimate of a Sectoral Model of Labor Mobility.” J.P.E. 98 (August): 827-52.

Larkins, Daniel. 2000. "Note on Rates of Return for Domestic Nonfinancial Corporations: Revised Estimates for 1960-98.” Survey Current Bus. 80 (June): 15-17.

Lucas, Robert E., Jr. 1978. "On the Size Distribution of Business Firms.” Bell J. Econ. 9 (Autumn): 508-23.

Marshall, Alfred. 1930. Principles of Economics: An Introductory Volume. 8th ed. London: Macmillan.

McGrattan, Ellen R., and Edward C. Prescott. 2005. "Taxes, Regulations, and the Value of U.S. and U.K. Corporations." Rev. Econ. Studies 72 (July): 76796.

Nelson, Richard R., and Sidney G. Winter. 1982. "The Schumpeterian Tradeoff Revisited.” A.E.R. 72 (March): 114-32.

Olley, G. Steven, and Ariel Pakes. 1996. "The Dynamics of Productivity in the Telecommunications Equipment Industry." Econometrica 64 (November): 1263-97. 
Poterba, James M. 1998. “The Rate of Return to Corporate Capital and Factor Shares: New Estimates Using Revised National Income Accounts and Capital Stock Data." Carnegie-Rochester Conf. Ser. Public Policy 48 (June): 211-46.

Prescott, Edward C., and Michael Visscher. 1980. "Organization Capital." J.P.E. 88 (June): 446-61.

Rosen, Sherwin. 1972. "Learning by Experience as Joint Production.” Q.J.E. 86 (August): 366-82.

Seskin, Eugene P., and Robert P. Parker. 1998. "A Guide to the NIPA's." Survey Current Bus. 78 (March): 26-68.

Topel, Robert H. 1991. "Specific Capital, Mobility, and Wages: Wages Rise with Job Seniority." J.P.E. 99 (February): 145-76.

Walters, Alan A. 1963. "Production and Cost Functions: An Econometric Survey." Econometrica 31 (January-April): 1-66. 